\title{
Diagnostic assessment of patients with interstitial lung disease
}

\author{
* Mridu Gulatia \\ a Department of Pulmonary \& Critical Care, Yale University School of Medicine, New Haven, Connecticut, USA
}

Originally submitted 20th November 2009; resubmitted 25th January 2010; revised version received 14th July 2010;

accepted 20th September 2010; online 20th April 2011

\begin{abstract}
The diagnosis of interstitial lung disease (ILD) is frequently delayed because clinical clues are neglected and respiratory symptoms are ascribed to more common pulmonary diagnoses such as chronic obstructive pulmonary disease (COPD) in the primary care setting. While ILD cases ultimately require referral to a pulmonologist, general practitioners can play a crucial role in recognising the need for, and initiating, a diagnostic evaluation. An initial assessment hinges upon a structured history and physical examination with careful attention paid to occupational, environmental and drug exposures as well as a history of symptoms suggesting connective tissue disease. Ultimately a surgical lung biopsy may be indicated, but high resolution computed tomography (HRCT) chest scans are essential to the diagnostic work-up since each ILD form is characterised by a specific pattern of abnormalities.

(C) 2011 Primary Care Respiratory Society UK. All rights reserved.

M Gulati. Prim Care Respir J 2011; 20(2): 120-127

doi:10.4104/pcrj.2010.00079
\end{abstract}

Keyw ords Interstitial Lung disease (ILD), Idiopathic Interstitial Pneumonia, Idiopathic Pulmonary Fibrosis (IPF), Connective Tissue Disease, Hypersensitivity Pneumonitis, Nonspecific Interstitial Pneumonia (NSIP), High Resolution CT (HRCT) Scan

\begin{tabular}{|c|c|}
\hline ntents & \\
\hline troduction & 120 \\
\hline Definition & 121 \\
\hline Classification ................................... & 121 \\
\hline Prevalence ........................................ & 121 \\
\hline Diagnostic tools . & 122 \\
\hline Early recognition of an ILD diagnosis & 122 \\
\hline$\ldots$ & 122 \\
\hline 1. General ....................................... & 122 \\
\hline 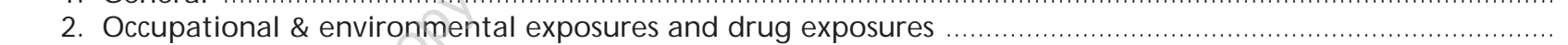 & 123 \\
\hline 3. Connective tissue disease ..... & 124 \\
\hline (.) & 124 \\
\hline (2) & 124 \\
\hline High resolution CT Scan & 125 \\
\hline Blood tests & 126 \\
\hline & 126 \\
\hline (1) & 127 \\
\hline & 27 \\
\hline
\end{tabular}

\section{Introduction}

Although interstitial lung disease (ILD) patients account for approximately $15 \%$ of the respiratory disease in general practice, ILD diagnosis can be delayed since clinicians often neglect early clinical clues or ascribe respiratory symptoms to more common pulmonary conditions such as chronic obstructive pulmonary disease (COPD). Primary care providers can play a critical role in expediting an ILD work-up by initiating an appropriate diagnostic evaluation. An initial work-up begins with a comprehensive history and physical examination with a meticulous occupational, environmental and drug history as well as an evaluation of any symptoms

\footnotetext{
* Corresponding author: Dr M ridu Gulati, Department of Pulmonary \& Critical Care, Yale University School of M edicine, 300 Cedar Street, TAC 441S, New Haven Connecticut 06520, USA. Tel: +1 2037852509 Fax: +1 2037853826 E-mail: elizabeth.tarquino@yale.edu
} 
suggesting connective tissue disease. Whilst a pulmonlogist may recommend a surgical lung biopsy, referrers can continue a diagnostic assessment by ordering high resolution computed tomography (HRCT) chest scans. Each ILD form is characterised by a specific pattern of HRCT abnormalities.

\section{Definition}

Interstitial lung disease (ILD), also referred to as diffuse parenchymal lung disease, refers to a heterogenous group of over 150 unrelated disorders. A distinct clinical presentation as well as radiographic and pathologic findings characterises each ILD form. Several key differences between the clinical presentation of the more frequent obstructive lung disease diagnoses and an ILD diagnosis are due to differences in the anatomic disease distribution. In most cases the pathology of ILD lies in the pulmonary interstitium, which consists primarily of connective tissue and refers to the space between the alveolar epithelial cells and the adjacent capillary endothelial cells. Therefore, in contrast to the wheezing caused by exhaling air through diffusely inflamed airways in asthmatic patients, clinicians detect inspiratory crackles in ILD patients, a finding caused by the opening of collapsed alveolar spaces surrounded by a fibrotic interstitium.

\section{Classification}

The American Thoracic Society has published an ILD classification scheme. ${ }^{1}$ While this classification scheme is based on histopathology, the most practical way to classify ILD is to divide between known versus unknown causes, or non-idiopathic versus idiopathic forms (see Figure 1). Referring practitioners can help detect non-idiopathic forms of ILD by reviewing relevant occupational, environmental and drug exposures as well as assessing for the presence of extrapulmonary symptoms suggestive of connective tissue disease. The non-idiopathic forms tend to have a better prognosis and response to therapy - for example, for patients with hypersensitivity pneumonitis, cessation of exposure to causative antigens such as avian proteins or mould can lead to immediate substantial improvement. Patients with ILD related to connective tissue disease usually present with the histopathologic entity referred to as 'nonspecific interstitial pneumonia' and have a better response to immunosuppressive therapy than patients with other forms of idiopathic ILD.

The idiopathic ILDs encompass several disease categories ranging from granulomatous diseases (which include sarcoidosis) to idiopathic interstitial pneumonias which include the well recognised entity of idiopathic pulmonary fibrosis (IPF). Mastering the ILD 'alphabet soup' is unnecessary, and it is only necessary to remember a few essential points. Sarcoidosis and idiopathic pulmonary fibrosis (IPF) are the two most common forms of idiopathic ILD, and the severity of sarcoidosis ranges

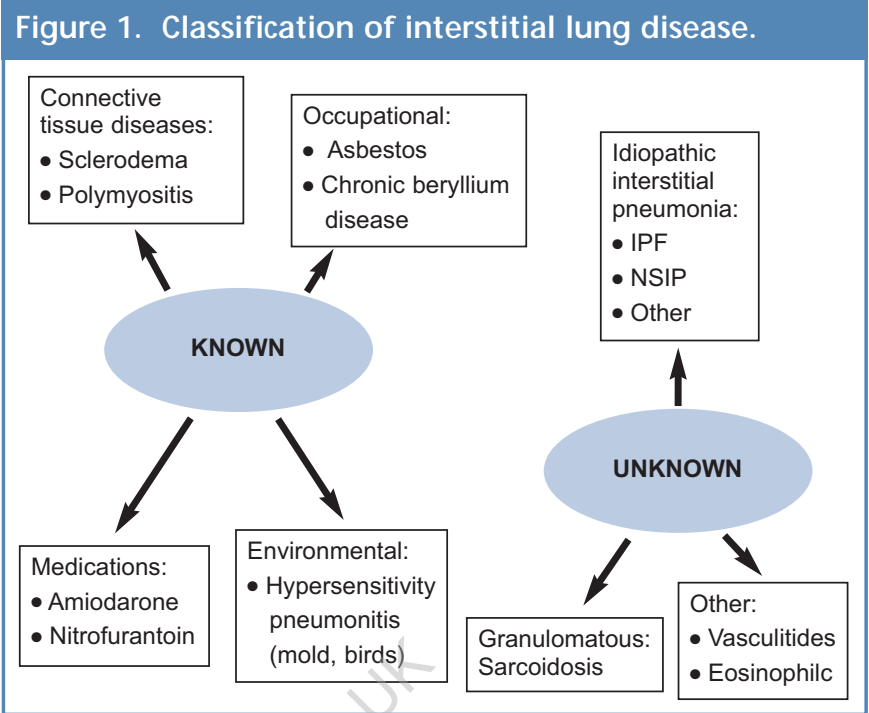

widely. In fact, some sarcoidosis patients may be completely asymptomatic despite the presence of floridly abnormal chest radiographs typically characterised by impressive mediastinal adenopathy. Symptomatic sarcoid patients often respond dramatically to steroids or other immunosuppressive agents.

idiopathic pulmonary fibrosis is another common form of an idiopathic ILD. Rather than being the end stage of all other ILDS, IPF is a specific form of an idiopathic interstitial pneumonia that usually occurs in older patients and has characteristic HRCT findings (peripheral and subpleural bibasilar reticulonodular opacities in association with traction bronchiectasis and honeycombing) and lung biopsy findings (temporal heterogeneity, honeycombing and fibroblastic foci). In general, IPF is characterised by more scarring and less inflammation and has a poorer prognosis than most other ILD forms.

Although the sheer number of different types of ILD can be overwhelming, differentiation between the various forms is critical given the significant variability in treatment response and prognosis. While steroid and immunosuppressive therapy are effective for certain ILD forms such as sarcoidosis, no effective drug therapy exists for idiopathic pulmonary fibrosis. Given their poor prognosis and a median survival of three to five years, IPF patients are frequently referred early for lung transplantation evaluation.

\section{Prevalence}

Although less frequent than COPD and asthma, ILD accounts for $15 \%$ of the respiratory disease in general practice. Few epidemiological studies exist. However, a frequently cited population-based registry from New Mexico reports a prevalence of 80.9 per 100,000 in males and 67.2 per 100,000 in females. ${ }^{2}$ IPF and sarcoidosis are the two most common ILD diagnoses. Occupationally-related ILD and connective tissue disease-associated ILD may each account for approximately $15 \%$ of all forms of ILD. 


\section{Diagnostic tools \\ Early recognition of an ILD diagnosis}

The following section summarises the critical components of an ILD diagnostic work-up (Table 1). As highlighted in this section, general practitioners (GPS) can help expedite an ILD work-up simply by recognising early clues in a patient's clinical presentation.

Each ILD entity classically presents as an acute, subacute or chronic illness (see Table 2). Many ILD diagnoses such as IPF and sarcoidosis, are chronic diseases, and ILD patients are frequently misdiagnosed as having COPD, particularly if there is a prior smoking history. Progressive dyspnoea and non-productive cough over years despite smoking cessation or in the absence of a smoking history as well as a lack of response to traditional inhaler therapy can suggest ILD. On physical examination, the absence of wheezing and the presence of inspiratory crackles may indicate ILD. IPF but not COPD patients have clubbing.

Clinicians routinely order chest radiographs in patients

Table 1. Diagnostic tools in patients with suspected interstitial lung disease history.

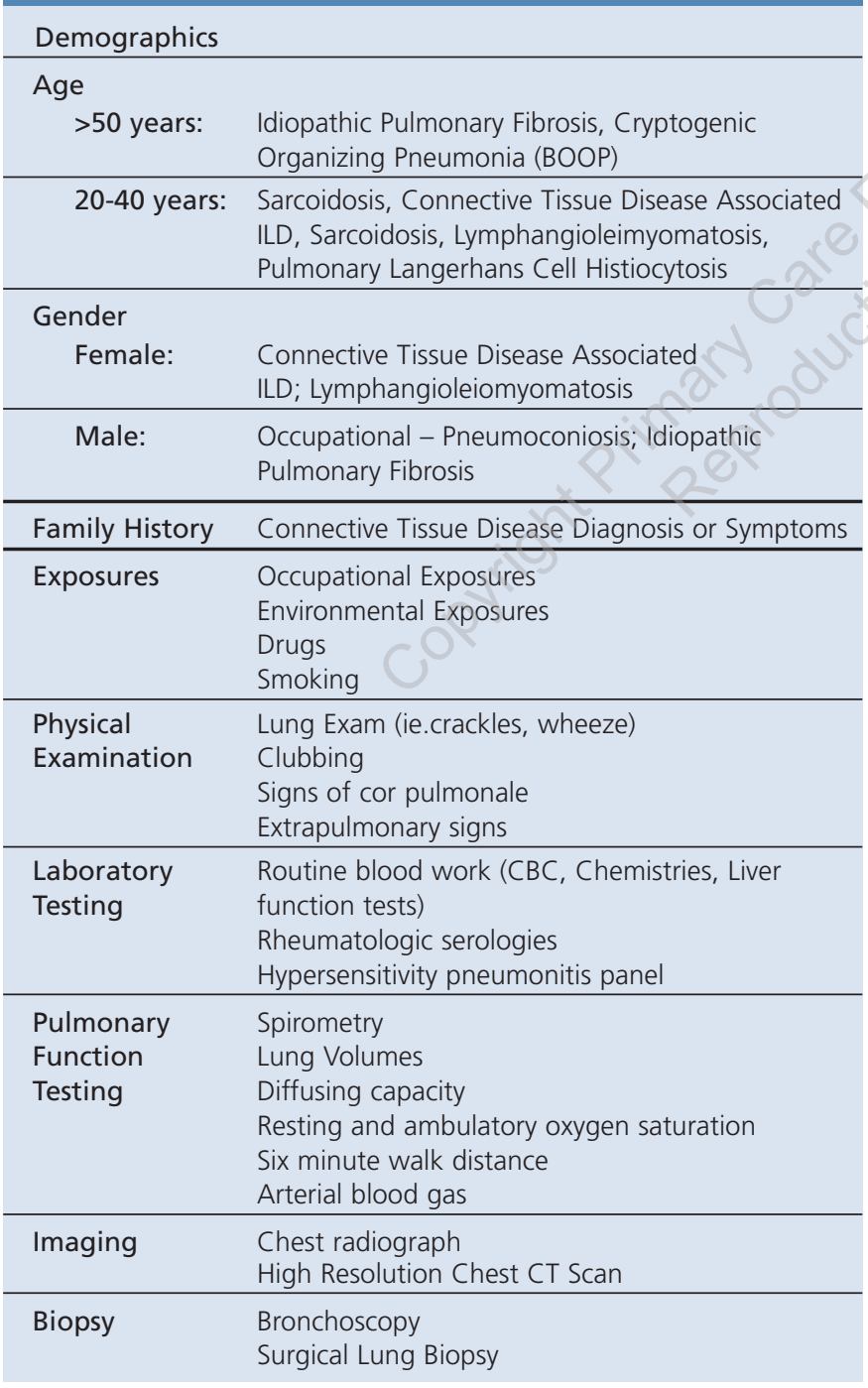

with chronic respiratory symptoms. Since COPD patients have largely normal chest radiographs, the presence of even the most subtle abnormalities such as increased interstitial markings or nodular opacities suggests ILD. Frequently, radiologists mistake chronic radiographic abnormalities in ILD for acute viral or bacterial pneumonias. Persistence of abnormalities despite antibiotic therapy and the lack of infectious symptoms suggest an ILD diagnosis. Patients with chronic respiratory disease or symptoms should undergo full pulmonary function testing; COPD patients have an obstructive pattern while ILD patients have a restrictive pattern. Finally, although ILD patients have normal resting oxygen saturations, ILD patients can become profoundly hypoxaemic on even minimal exertion.

\section{History}

\section{General}

Once suspected, historical clues alone may implicate a specific ILD diagnosis (see Table 1). Information regarding demographics as well as occupational and environmental exposures, medications, smoking status and connective tissue disease history is invaluable. ${ }^{3,4}$ Simple demographic data can be useful; for example, IPF patients are typically older and male while patients with connective tissue disease-associated ILD are younger and female. Sarcoidosis patients are younger. There is a higher prevalence of sarcoidosis among African Americans. Extrapulmonary manifestations and chronic progressive disease are also more frequent in African Americans with sarcoidosis.

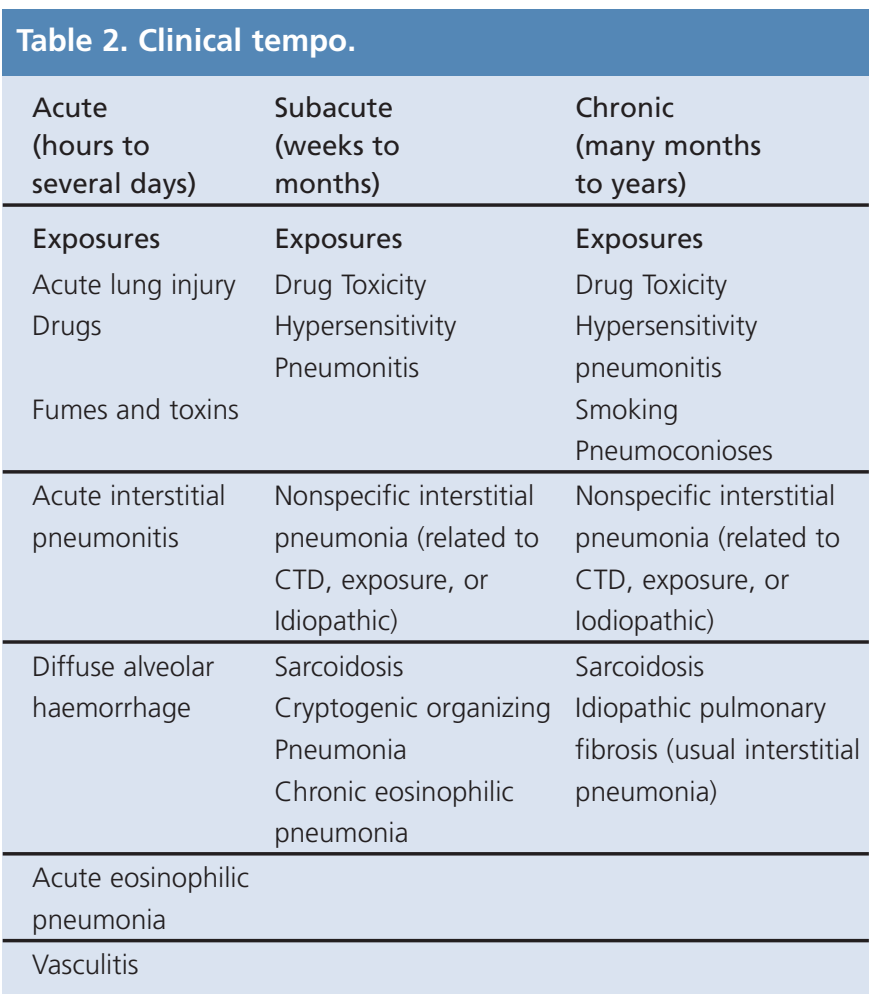


Except for extremely rare ILD forms such as Hermansky Pudlak or metabolic storage diseases, genetic associations only modestly increase the risk for more common ILD forms such as sarcoidosis and IPF.

While smoking is a strong risk factor for certain rare forms of ILD such as Respiratory bronchiolitis-Interstitial Lung Disease/Desquamative Interstitial Pneumonia and Pulmonary Langerhans' Cell Histiocytosis, smoking only slightly increases the risk for the much more prevalent disease of idiopathic pulmonary fibrosis. ${ }^{5}$

\section{Occupational \& environmental and drug exposures}

Primary care clinicians enjoy longstanding relationships with patients and have a rich source of patient information regarding exposures (Table 3). Early detection of potential respiratory toxins can lead to early exposure cessation and clinical improvement.

Although often indistinguishable from idiopathic ILD forms, occupational exposures may account for approximately $15 \%$ of ILD cases (Table 4). For example, asbestosis in a shipyard worker can be confused with IPF, and chronic beryllium disease in a nuclear industry worker can be mistaken for sarcoidosis. Since disease may present years after exposure cessation, all past and present jobs should be recorded. ${ }^{6,7}$ The presence of respiratory illnesses in co-workers, inconsistent use of protective respirators as well as poor industrial hygiene controls leading to a "dusty" work environment are frequently reported.

Over 300 environmental exposures have been implicated

Table 3. Principals of occupational and environmental

history.

Complete employment history
Job
Job activities and tasks
Years worked
Temporal association between symptoms and work and specific
$\quad$ work activities
Presence of sick coworkers
Exposure
Assessment of visible dust or odours on surfaces and in air
Hours worked
Engineering controls such as local exhaust ventilation
Personal protective equipment (respirators)
Materials worked (Material Safety Data sheets)
Household
Exposures or job activities of all household members (exposure to
household member's dusty work clothes)
Hobbies
Pets (birds)
Water damage (mold exposure)
Hot tub usage (Mycobacterium Avium Complex)

as causes of hypersensitivity pneumonitis, another nonidiopathic ILD category ${ }^{8}$ (see Table 5). In a recent Mayo Clinic series, exposure to birds and hot tubs (Mycobacterium avium complex exposure) accounted for $34 \%$ and $21 \%$ of hypersensitivity pneumonitis cases, respectively. Exposures to

Table 4: Examples of occupational exposures associated with interstitial lung disease.

\begin{tabular}{|c|c|c|}
\hline Agent & Exposure Settings & HRCT Findings \\
\hline \multicolumn{3}{|c|}{ Fibrous Dust } \\
\hline Asbestos & $\begin{array}{l}\text { Construction, building, } \\
\text { mining, shipbuliding, } \\
\text { automobile and } \\
\text { railroad work, } \\
\text { insulation }\end{array}$ & $\begin{array}{l}\text { Lower zone } \\
\text { predominant } \\
\text { reticular opacities, } \\
\text { honeycombing, } \\
\text { pleural disease }\end{array}$ \\
\hline
\end{tabular}

\begin{tabular}{lll}
$\begin{array}{l}\text { Inorganic nonfibrous dust } \\
\text { Crystalline } \\
\text { silica }\end{array}$ & $\begin{array}{l}\text { Mining, construction, } \\
\text { sandblasting, } \\
\text { granite/stone work, } \\
\text { road work, } \\
\text { tunneling }\end{array}$ & $\begin{array}{l}\text { Upper zone } \\
\text { predominant } \\
\text { nodular disease, } \\
\text { progressive massive } \\
\text { fibrosis, hilar adenopathy }\end{array}$ \\
\hline Coal dust & Coal mining & $\begin{array}{l}\text { Upper zone predominant } \\
\text { nodular disease, } \\
\text { progressive massive } \\
\text { fibrosis }\end{array}$ \\
\hline Metals & & \\
Beryllium & $\begin{array}{l}\text { Nuclear weapons, } \\
\text { electronics, aerospace, } \\
\text { ceramics, machining, } \\
\text { dental prostheses, alloy } \\
\text { machining }\end{array}$ & $\begin{array}{l}\text { Middle and upper zone } \\
\text { predominant } \\
\text { nodular infiltrates } \\
\text { (similar to sarcoidosis) }\end{array}$ \\
& &
\end{tabular}

Table 5. Examples of environmental exposures associated with hypersensitivity pneumonitis.

\begin{tabular}{|c|c|c|}
\hline Disease & Antigen & Source \\
\hline \multicolumn{3}{|c|}{ Fungal and bacterial } \\
\hline Farmers Lung & $\begin{array}{l}\text { Saccharopolyspora } \\
\text { rectivirgula, } \\
\text { Thermactinomyces vulgaris }\end{array}$ & Moldy hay, grain \\
\hline $\begin{array}{l}\text { Metal } \\
\text { working fluid }\end{array}$ & $\begin{array}{l}\text { Mycobacterium } \\
\text { immunogenum }\end{array}$ & Metal working fluid \\
\hline Hot tub lung & $\begin{array}{l}\text { Mycobacterium avium } \\
\text { complex, } \\
\text { Cladosporium }\end{array}$ & $\begin{array}{l}\text { Hot tubs, } \\
\text { mold on ceiling }\end{array}$ \\
\hline $\begin{array}{l}\text { Summer type } \\
\text { pneumonitis }\end{array}$ & $\begin{array}{l}\text { Trichosporon } \\
\text { cutaneum }\end{array}$ & $\begin{array}{l}\text { Contaminated old } \\
\text { houses }\end{array}$ \\
\hline \multicolumn{3}{|l|}{ Animal proteins } \\
\hline $\begin{array}{l}\text { Pigeon breeder's } \\
\text { disease }\end{array}$ & $\begin{array}{l}\text { Bird droppings, serum } \\
\text { feathers }\end{array}$ & $\begin{array}{l}\text { Birds: parakeets, } \\
\text { Pigeons, chickens }\end{array}$ \\
\hline \multicolumn{3}{|l|}{ Chemicals } \\
\hline $\begin{array}{l}\text { Chemical workers } \\
\text { lung }\end{array}$ & Isocyanates & $\begin{array}{l}\text { Polyurethane foams } \\
\text { Spray paints, } \\
\text { Elastomers, } \\
\text { special glues }\end{array}$ \\
\hline
\end{tabular}


agricultural antigens found on farms and household mould exposure accounted for $11 \%$ and $9 \%$ of cases, respectively. ${ }^{9}$ Certain antigens (i.e. avian antigens) are more antigenic than others, and even common household exposures such as mould can cause hypersensitivity pneumonitis.

Medications - including antibiotics, chemotherapeutic agents and antiarrhythmic agents - can cause ILD. Whilst the toxicity of drugs such as amiodarone is known, clinicians overlook the potential toxicity of novel therapeutics such as biologic agents or over-the-counter drugs. While primary care clinicians may easily discern acute temporal associations between drug administration and respiratory symptoms, the relationship between chronic drug exposure and ILD is often less apparent. Reactions can be dose-dependent or idiosyncratic. ${ }^{10}$ A database of drugs associated with pulmonary toxicity is available at www.pneumotox.com. ${ }^{11}$

\section{Connective tissue disease}

Contrary to sub-specialists who focus on specific organ systems, GPs assess the entire patient. This generalised approach is invaluable in the work-up of the suspected ILD patient since approximately $15-20 \%$ of ILD patients have a concomitant diagnosis of connective tissue disease. ILD may also be the initial presentation of connective tissue disease, and systematic manifestations may follow months to years after the appearance of pulmonary disease. GPs should conduct a careful review of extrapulmonary symptoms and assess for the presence of any symptom constellation associated with a particular connective tissue disease (Table 6). For example, scleroderma patients may report skin thickening (i.e. sclerodactyly), Raynaud's phenomenon, and gastroesophageal reflux. Polymyositis/dermatomyositis patients may present with typical skin lesions (violaceous scaling papules - Gottron's papules and facial heliotrope

Table 6. Symptoms associated with connective tissue disease.

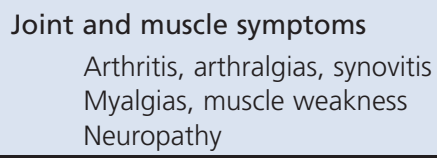

Raynaud's

Gastrointestinal symptoms (GERD)

\section{Sicca symptoms}

Skin

Malar rash/Photosensitivity

Machinist hands

Gottron's papules

Sclerodactyly, digital ulcers

Telangiectasias

Chest pain

Eye abnormalities (uveitis,scleritis, ulcers) rash), mechanic's hands, and muscle disease. ${ }^{12,13}$ Patients with connective tissue disease-associated ILD often have a better response to immunosuppressive therapy and a better prognosis compared to patients with other ILD forms such as IPF. Furthermore, screening for connective tissue disease may lead to early treatment of other extrapulmonary systemic complications such as renal disease in scleroderma patients.

\section{Physical examination}

A thorough ILD work-up requires a comprehensive physical examination. Since ILD patients are often misdiagnosed with COPD, GPs should take note of physical exam findings that can differentiate a diagnosis of ILD from COPD. Most ILD patients do not have wheezing, a finding caused by airway disease, but they do have inspiratory crackles, a finding caused by the opening of collapsed alveolar spaces amidst a fibrotic interstitium. Clubbing is seen in certain forms of ILD such as IPF but is not found in COPD patients. Finally, the presence of extrapulmonary findings argues against a diagnosis of COPD.

Certain constellations of findings point to specific diagnoses. For example, lymphadenopathy combined with certain skin findings such as erythema nodosum or lupus pernio suggest sarcoidosis. Arthralgias are common in ILD but active synovitis suggests connective tissue disease. Scleroderma patients typically have sclerodactyly, Raynaud's phenomenon, and telangiectatic lesions. Proximal muscle weakness along with typical skin lesions (violaceous scaling papules - Gottron's papules, facial heliotrope rash) and mechanic's hands may point to a diagnosis of Polymyositis/dermatomyositis.

\section{Pulmonary function testing}

Primary care clinicians can avoid diagnostic delays in ILD diagnosis by ordering complete pulmonary function testing in patients with chronic respiratory symptoms. Primary care offices frequently administer routine office spirometry. Reduced forced vital capacity (FVC) can suggest the presence of a restrictive lung disease and perhaps ILD, particularly given the appropriate clinical scenario; however, since COPD patients may also have reductions in FVC due to severe air trapping, GPs cannot confidently diagnose restrictive lung disease using office spirometry alone. Full pulmonary function testing, including the measurement of total lung capacity, is necessary to diagnose the presence of the restrictive ventilatory defect typically seen in ILD patients. Available in most pulmonary practices, pulmonary function testing includes spirometry, lung volumes and diffusing capacity and provides critical information regarding disease severity and prognosis. ${ }^{14,15}$ Whilst COPD patients have an obstructive ventilatory defect with a reduced forced expiratory volume in one second $\left(\mathrm{FEV}_{1}\right)$ / FVC ratio, ILD patients have a restrictive ventilatory defect with reduced total lung capacity. An impaired diffusion capacity may be the first abnormality 
present. The presence of oxygen desaturation at rest or with ambulation portends a poorer prognosis and can lead to treatment with oxygen supplementation. Six-minute walk tests detect the presence of oxygen desaturation during ambulation and distance walked.

\section{High resolution CT scanning}

During a routine work-up of respiratory symptoms, GPs often order plain chest radiographs (CXRs). Routine CXRs in ILD patients often have subtle abnormalities such as ground glass abnormalities, nodular opacities or increased reticular markings, and less experienced radiologists often miss such subtle findings. In addition to complete pulmonary function tests, GPs should order high resolution computed tomography (HRCT) chest scans, if available without specialist referral, for patients with suspected ILD. Compared to a standard CT Scan, HRCT provides superior spatial and contrast resolution.

\begin{tabular}{|c|c|c|}
\hline Diagnosis & $\begin{array}{l}\text { Typical HRCT } \\
\text { Features }\end{array}$ & $\begin{array}{l}\text { Typical } \\
\text { Distribution } \\
\text { on CT }\end{array}$ \\
\hline $\begin{array}{l}\text { Idiopathic } \\
\text { Pulmonary } \\
\text { Fibrosis/Usual } \\
\text { Interstitial } \\
\text { Pneumonia } \\
\end{array}$ & $\begin{array}{l}\text { Reticular, honeycombing, } \\
\text { traction bronchiectasis }\end{array}$ & $\begin{array}{l}\text { Peripheral, } \\
\text { subpleural } \\
\text { basal, } \\
\text { lower lung zones }\end{array}$ \\
\hline $\begin{array}{l}\text { Nonspecific } \\
\text { Interstitial } \\
\text { Pneumonia }\end{array}$ & $\begin{array}{l}\text { Ground glass attenuation } \\
\text { and reticular lines }\end{array}$ & Peripheral \\
\hline $\begin{array}{l}\text { Cryptogenic } \\
\text { Organizing } \\
\text { Pneumonia }\end{array}$ & Consolidation & $\begin{array}{l}\text { Peripheral, } \\
\text { peribronchial }\end{array}$ \\
\hline $\begin{array}{l}\text { Acute Interstitial } \\
\text { Pneumonia }\end{array}$ & $\begin{array}{l}\text { Consolidation, } \\
\text { ground glass }\end{array}$ & Diffuse \\
\hline $\begin{array}{l}\text { Desquamative } \\
\text { Interstitial } \\
\text { Pneumonia }\end{array}$ & $\begin{array}{l}\text { Ground glass } \\
\text { attenuation, } \\
\text { reticular lines }\end{array}$ & Lower lung zones \\
\hline $\begin{array}{l}\text { Hypersensitivity } \\
\text { Pneumonitis }\end{array}$ & $\begin{array}{l}\text { Ground glass, } \\
\text { centrilobular } \\
\text { nodules, air trapping } \\
\text { (mosaic attenuation) }\end{array}$ & $\begin{array}{l}\text { Upper and mid } \\
\text { lung zones }\end{array}$ \\
\hline Sarcoidosis & $\begin{array}{l}\text { Hilar adenopathy, nodular } \\
\text { opacities, beading and } \\
\text { thickening along } \\
\text { peribronchiovascular bundles }\end{array}$ & $\begin{array}{l}\text { Upper and mid } \\
\text { lung zones }\end{array}$ \\
\hline Asbestosis & $\begin{array}{l}\text { Reticular, honeycombing, } \\
\text { traction bronchiectasis, } \\
\text { pleural plaques marker of } \\
\text { asbestos exposures }\end{array}$ & Lower lung zones \\
\hline Silicosis & $\begin{array}{l}\text { Nodular opacities (may } \\
\text { coalesce into nodules } \\
\text { greater than } 10 \mathrm{~mm} \text { in size } \\
\text { progressive massive fibrosis), } \\
\text { hilar adenopathy with } \\
\text { calcifications }\end{array}$ & $\begin{array}{l}\text { Upper and mid } \\
\text { lung zones }\end{array}$ \\
\hline
\end{tabular}

Abnormalities on HRCT can be assessed for patterns (e.g. reticular markings, consolidation, ground glass, nodules), anatomic distribution (i.e. peripheral vs. central, upper vs. lower), and associated findings (i.e. mosaic attenuation, hilar adenopathy). Intravenous contrast can help distinguish lymphadenopathy from surrounding vasculature in sarcoidosis patients but is not generally needed.

Different HRCT patterns (Table 7) suggest different diagnoses. ${ }^{16-18}$ For example, an elderly patient with an insidious history of dry cough and dyspnoea who has an HRCT with findings classic for IPF - the presence of subpleural reticular markings, traction bronchiectasis and honeycombing in a lower lobe distribution - does not need a lung biopsy (see Figure 2). The presence of hilar adenopathy and nodules in a perilymphatic distribution in the upper and mid lung zones suggests sarcoidosis (Figure 3).
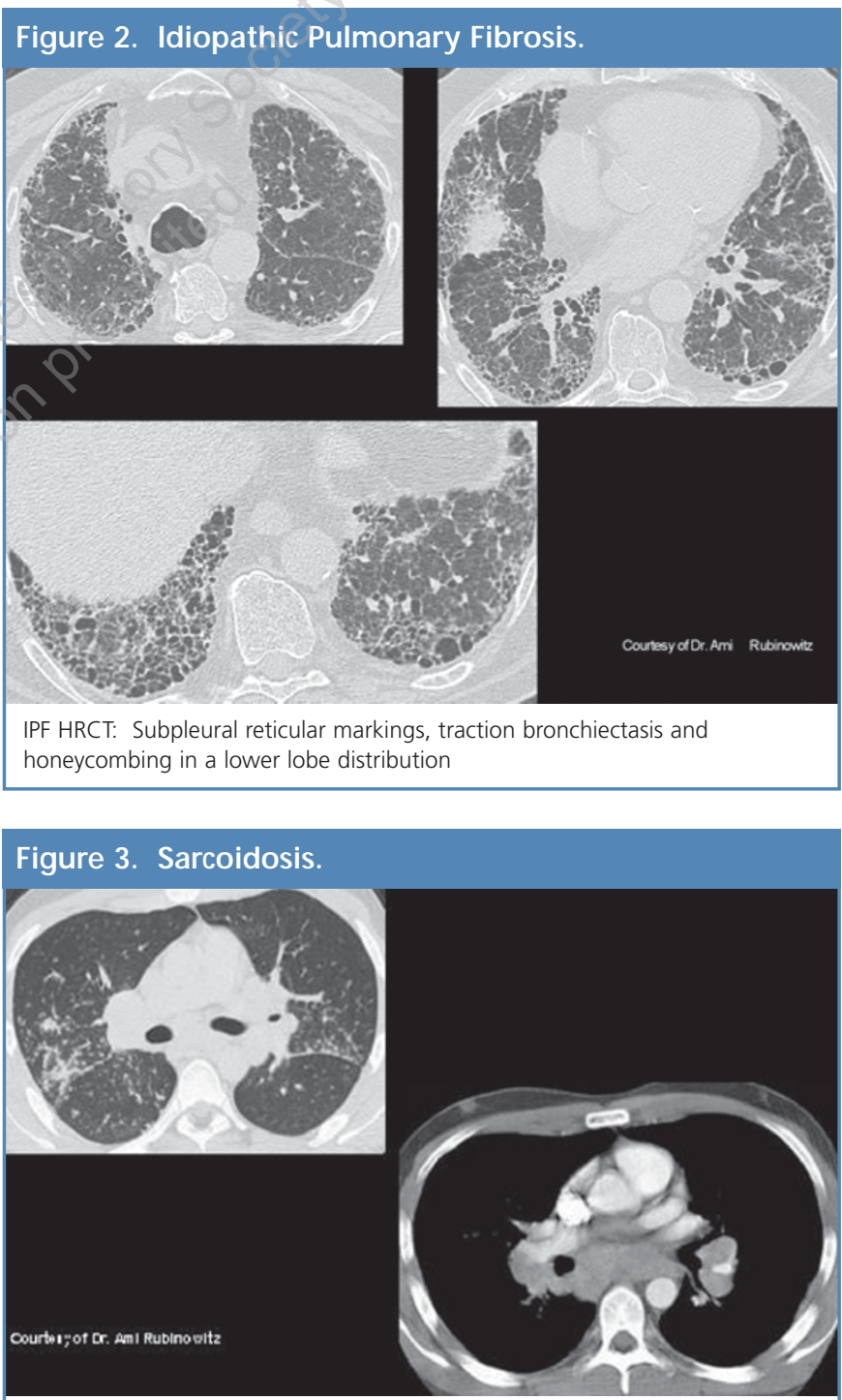

Sarcoidosis HRCT: Hilar and mediastinal lymphadenopathy, beaded appearance and thickening of brochovascular bundles, nodules along bronchi 
General radiologists are familiar with radiographic patterns of IPF and sarcoidosis but often neglect subtle findings seen in other ILD forms such as ground glass abnormalities and centrilobular nodular distribution. Appreciating such details is critical since each ILD form has a distinct set of therapeutic options and prognosis. Hence, after ordering HRCTs, GPs should refer to a pulmonologist for a more accurate assessment.

\section{Blood tests}

Extensive laboratory testing in the ILD work-up is typically performed by a pulmonologist. Blood testing (Table 8) is useful in demonstrating the presence of systemic involvement, the detection of connective tissue disease, and in establishing a causative antigen in hypersensitivity pneumonitis patients. Initial blood testing includes a full differential blood count, serum urea, electrolytes, creatinine and liver function tests. Hypercalcemia is often seen in sarcoidosis patients. Renal involvement is seen in certain connective tissue diseases such as scleroderma and lupus. Although false negative and positive testing is common, autoantibody testing can help diagnose a coexisting connective tissue disease. A complete blood test work-up includes rheumatoid factor and antinuclear antibodies with extractable nuclear antigens - Ro and La (Sjogren's), Scl-70

Table 8. Laboratory studies in the workup interstitial lung disease.

\begin{tabular}{|c|c|}
\hline Laboratory Study & Most Common Disease Association \\
\hline \multicolumn{2}{|c|}{ All Interstitial Lung Disease Patients } \\
\hline \multicolumn{2}{|l|}{ Routine blood tests } \\
\hline $\begin{array}{l}\text { Full blood count } \\
\text { Urea and creatinine } \\
\text { Electrolytes } \\
\text { Liver Function tests } \\
\text { Bone screening including } \\
\text { serum calcium level }\end{array}$ & \\
\hline \multicolumn{2}{|c|}{ Suspected Connective Tissue Disease } \\
\hline ESR & Any Connective Tissue Disease \\
\hline CRP & Any Connective Tissue Disease \\
\hline ANA & Any Connective Tissue Disease \\
\hline Anti ds-DNA (SLE) & Systemic Lupus Erythematosis \\
\hline Anti-Smith & Systemic Lupus Erythematosis \\
\hline Rheumatoid Factor & Rheumatoid Arthritis \\
\hline $\begin{array}{l}\text { Anti-cyclic citrullinated } \\
\text { peptide antibody }\end{array}$ & Rheumatoid Arthritis \\
\hline Anti-SSA/Ro & Sjogren's \\
\hline Anti-SSB/La & Sjogren's \\
\hline Anti Scl-70 & Scleroderma \\
\hline Anti-RNP & Mixed CTD \\
\hline $\begin{array}{l}\text { Aldolase and myositis } \\
\text { panel }\end{array}$ & Polymyositis \\
\hline C, P-ANCA & Wegener's, Microscopic polyangiitis \\
\hline Anti-GBM & Goodpasture's \\
\hline \multicolumn{2}{|l|}{ Hypersensitivity Pneumonitis } \\
\hline Serum precipitins & Hypersensitivity pneumonitis \\
\hline
\end{tabular}

(scleroderma), Jo-I (Polymyositis/Dermatomyositis), and RNP (Mixed Connective Tissue Disease).

Hypersensitivity pneumonitis bloods test for the presence of $\lg G$ antibodies to environmental antigens and differ from the lgE antibody testing performed in standard allergy blood testing. Most outpatient laboratories test for a small specific set of antibodies to several mould species and avian proteins. False positive testing and false negative testing is common. False positive testing may simply be a marker of exposure while false negative testing may be due to testing for the wrong antigen or removal from exposure. Given the high rates of false positives and negatives, the blood test results following autoantibody testing for connective and hypersensitivity pneumonitis should not supplant a clinical diagnosis.

\section{Biopsy}

A pulmonologist should address the decision regarding biopsy. Factors to be considered include HRCT findings, history of exposures, and the risks and benefits of an invasive procedure given the patient's clinical status and patient preference. ${ }^{19} \mathrm{~A}$ diagnosis of IPF can be made without a biopsy in patients with a classic constellation of HRCT findings, including lower lobe predominance of abnormalities, traction bronchiectasis, honeycombing and subpleural reticular markings (Figure 2). Thus, a bird owner with an HRCT showing characteristic hypersensitivity pneumonitis features - centrilobular nodules, ground glass opacities, air trapping, and abnormalities in an upper and mid lung zone distribution - and positive serum precipitins, does not need a biopsy (Figure 4).

If a biopsy is indicated, bronchoscopy with transbronchial biopsy does not usually yield sufficient tissue and a surgical lung biopsy is needed..$^{20}$ Infrequently, bronchoscopy can be useful, such as in the diagnosis of sarcoidosis or hypersensitivity pneumonitis. When indicated, video assisted thorascopic surgery generally has a relatively low mortality rate of less than $2 \%$.

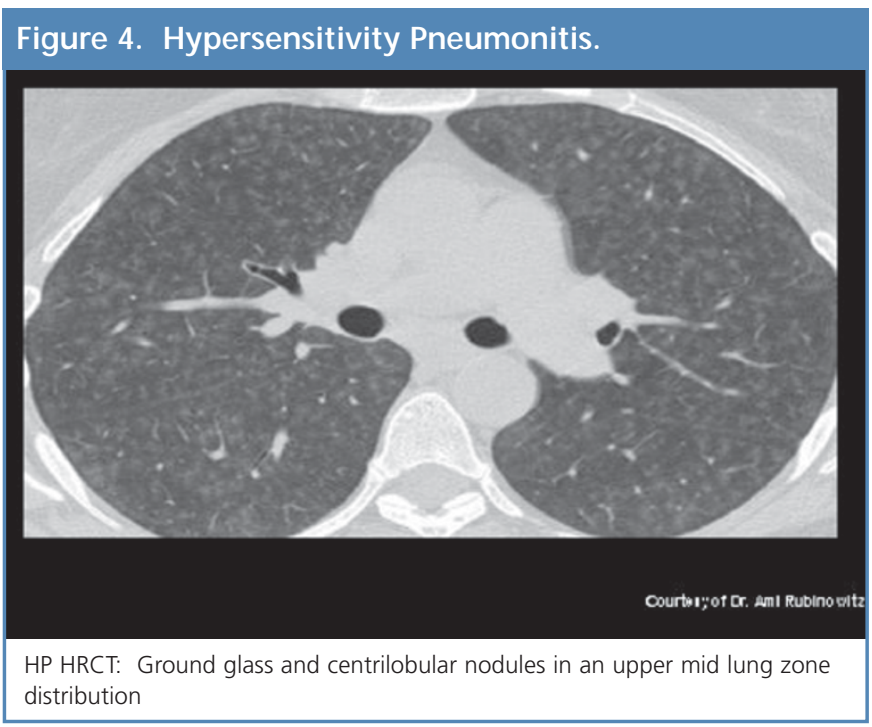


Surgeons should obtain large lung tissue sample sizes and specimens should be reviewed by experienced pulmonary pathologists.

Although the current ILD classification scheme is based on specific histopathology, problems with even this "gold standard" exist. Firstly, occupational, environmental and drug exposures have been associated with the development of histopathologic forms of ILD that are indistinguishable from the idiopathic ILDs for example, an asbestos worker may develop histopathologic findings similar to those found in IPF patients, and workers exposed to beryllium may develop a syndrome identical to sarcoidosis.

Another challenge facing the histopathologic classification scheme is the substantial interobserver variability existing between pathologists, particularly with diagnoses other than sarcoidosis and IPF. ${ }^{21}$ Furthermore, biopsies from different lobes may reveal different histopathologies. This occurs typically in patients who have evidence of nonspecific interstitial pneumonia in one lobe and findings consistent with idiopathic pulmonary fibrosis in another lobe; the prognosis of these patients is similar to that seen in IPF patients. ${ }^{22}$

The limitations of the present classification scheme underscore the fact that even histopathology does not supplant a comprehensive history and physical examination that assesses for relevant exposures or a concomitant connective tissue disease diagnosis.

\section{Conclusions}

Interstitial lung diseases encompass a heterogeneous collection of lung diseases and include diseases with known and unknown causes. While ILD cases often require referral to a pulmonologist, GPs can prevent diagnostic delays by recognising clinical clues, reviewing relevant exposures, and uncovering the presence of possible connective tissue disease, as well as ordering HRCT chest scans and pulmonary function tests if possible. Although GPs often first consider idiopathic ILD forms such as IPF, early recognition of possible non-idiopathic ILD can lead to the early cessation of possible toxic exposures as well as therapy with immunosuppressive therapy for patients with connective tissue disease-related ILD.

\section{Conflict of interest declaration}

None.

\section{References}

1. American Thoracic Society, European Respiratory Society. American Thoracic Society/European Respiratory Society International Multidisciplinary Consensus Classification of the Idiopathic Interstitial Pneumonias. This joint statement of the American Thoracic Society (ATS), and the European Respiratory Society (ERS) was adopted by the ATS board of directors, June 2001 and by the ERS Executive
Committee, June 2001. Am J Respir Crit Care Med 2002;165(2):277-304.

2. Coultas DB, Zumwall RE, Black WC, Sobonya RE. The epidemiology of interstitial lung diseases. Am J Respir Crit Care Med 1994;150(4):967-72.

3. King TE Jr. Clinical advances in the diagnosis and therapy of the interstitial lung diseases. Am J Respir Crit Care Med 2005;172(3):268-79. http://dx.doi.org/10.1164/rccm.200503-4830E

4. Schwarz MI, King TE, Raghu G. Approach to the evaluation and diagnosis of interstitial lung disease. In: King TE, Schwarz MI, eds. Interstitial Lung Disease. Ontario, Canada: BC Decker; 2003:1-30.

5. Caminati A, Harari S. Smoking-related interstitial pneumonias and pulmonary Langerhans cell Histiocytosis. Proc Am Thorac Soc 2006;3(4):299-306. http://dx.doi.org/10.1513/pats.200512-135TK

6. Glazer CS, Newman LS. Occupational interstitial lung disease. Clin Chest M ed 2004;25(3):467-78.

7. Neurnberg AM, Christiani DC. The future of occupationally related diffuse lung disease. Semin Respir Crit Care Med 2008;29(6):680-4. http://dx.doi.org/10.1055/s-0028-1101278

8. Selman M. Hypersensitivity pneumonitis: a multifaceted deceiving disorder. Clin Chest Med 2004;25:531. http://dx.doi.org/10.1016/j.ccm.2004.04.001

9. Hanak V, Golbin JM, Ryu JH et al. Causes and presenting features in 85 consecutive patients with hypersensitivity pneumonitis. Mayo Clinic Proceedings 2007;82(7):812-16. http://dx.doi.org/10.4065/82.7.812

10. Camus P, Bonniaud P, Fanton A, Camus C, Baudaun N, Foucher P. Druginduced and iatrogenic infiltrative lung disease. Clin Chest Med 2004;25(3):479-519.

11. www.pneumotox.com

12. Tzelespis GE, Toya SP. Moustopoulos HM. Occult connective tissue diseases mimicking idiopathic interstitial pneumonias. Eur Respir J 2008;31(1):11-20.

13. Strange $C$, Highland KB. Interstitial lung disease in the patient who has connective tissue disease. Clin Chest Med 2004;25(3)549-59. http://dx.doi.org/10.1016/j.ccm.2004.05.009

14. Lama VN, Martinez FJ. Resting and exercise physiology in interstitial lung diseases. Clin Chest Med 2004;25:435. http://dx.doi.org/ 10.1016/j.ccm.2004.05.005

15. Chetta A, Marangio $E$, Olivieri D. Pulmonary function testing in interstitial lung diseases. Respiration 2004;71:209. http://dx.doi.org/10.1159/000077416

16. Lynch DA, David Godwin J, Safrin S, et al. High-resolution computed tomography in idiopathic pulmonary fibrosis: diagnosis and prognosis. Am J Respir Crit Care Med 2005;172(4):488-93. http://dx.doi.org/ 10.1164/rccm.200412-17560C

17. Hunninghake GW, Zimmerman MB, Schwartz DA, et al. Utility of a lung biopsy for the diagnosis of idiopathic pulmonary fibrosis. Am J Respir Crit Care Med 2001;164(2):193-6.

18. Johkoh $\mathrm{T}$, Muller NL, Cartier $\mathrm{Y}$, et al. Idiopathic interstitial pneumonias: Diagnostic accuracy of thin-section CT in 129 patients. Radiology 1999; 211:555.

19. Hunninghake GW, Zimmerman MB, Schwartz DA, et al. Utility of a lung biopsy for the diagnosis of idiopathic pulmonary fibrosis. Am J Respir Crit Care Med 2001;164(2):193-6.

20. King TE, Jr. Bronchoscopy in Interstitial Lung Disease. In: Textbook of Bronchoscopy, Feinsilver, SH, Fein, AM (Eds), Williams \& Wilkins, Baltimore, 1995, p. 185.

21. Nicholson $A$, Addis $B$, Bharucha $H$, et al. Inter-observer variation between pathologists in diffuse parenchymal lung disease. Thorax 2004;59(6):500-05. http://dx.doi.org/10.1136/thx.2003.011734

22. Flaherty KR, Travis WD, Colby TV, et al. Histopathologic variability in usual and nonspecific interstitial pneumonia. Am J Respir Crit Care Med 2001;164(9): $1722-7$. 